\title{
Opinion on Nanorobotics, Nanoscience and Nanotechnol ogy as Nanomedicines for Future Medical Practices
}

\author{
Sadique Shaikh ${ }^{1}$ and Tarique Shaikh*2 \\ ${ }^{1}$ KYDSC Trust's, Institute of Management \& Scie8nce (IMS), India
}

${ }^{2}$ R.D. Memorial Ayurvedic College and Hospital, India

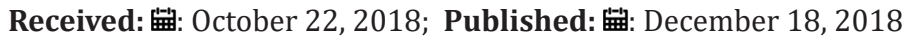

*Corresponding author: Tarique Shaikh, RD Memorial Ayurvedic College and Hospital, Bhopal, MP, India

\begin{abstract}
All of you much about the all fields of Nano research domains in generals but here intension is specific in the field of medical sciences, practices and new surgery methods. I am in this communication tried to help you to explore new researches and practices using below intriguing basic model in various direction of medical sciences and practices.
\end{abstract}

Keywords: Nanoparticles; Nanorobots; Biological Nonomotors; Nanoscience; Nanotechnology; NEMS; ATP Motors; Softrobotics; Molecular Chemistry; Synthetic Biology; Nanopowders

\section{Opinion}

Above model is lucid representation of all possible research domains of Nano regime in medical science and practices as per my opinion. I am confined my self only for Nanomedicines and how showcased how various sub-fields available in Nano regime. I labeled this model as "Nanomedicines explore and Practices model", where I exhibits six possible branches of nano regime where research in progress or possible to conduct for medical practice. The first domain is softrobotics and nanometers, in this sub-field researchers can work to design, growth or fabricate such tiny robots or motors which easily input in human body, skull or in any part of body to heal, repair or kill viruses, bacteria's etc. for example Nano-robot or Nano-motor entered in body which has intelligence and processing ability to detect and kill cancer cells. The second sub-field is Molecular Chemistry often called integrated chemistry or hybrid chemistry where atoms and molecules engineering and manipulation take place to create such nano molecular structures those can be use as excellent and instant medical diagnosis and treatment.

The third segment is nano-powders and nanoparticles those are zero-dimensional structures and each tiny particle itself act like tablet or capsule for human treatment. The forth domain is Nano-Electro-Mechanical-Systems (NEMS) this is the research and practice area where low dimensional semiconductor or hybrid structures fabricated on 10-9 scale which are like automatic mobile or surgical robots or diagnostic robots having mechanical touch. The fifth sub-fields which would be possible to implement in near future or being rare in use in medical practice is diagnosis and treatment using Quantum Dots (QDs) which zero-dimensional semiconductors and very useful to detect various kind of viruses and heal skin related diseases. The last sub-field is synthetic biology which is itself one of the vast domain of research having various sub-domains. In synthetic biology bio-medical robots engineered using tissue and DNA engineering for medical surgery, diagnose and medicinal purpose.

\section{Conclusion}

In this communication I tried to pay your attention on all possible research domains in the field of medical science, surgery, medicine using nano regime with the help of "Nanomedicines explore and Practices model". My intention through this opinion not to give you depth of all domains but to give you direction to choose which comfortable for you to conduct research in medical practice from Nanoscience, Nanorobotics and nanotechnology.

\section{Acknowledgement}

I would like to credit this work to my loving wife Safeena Khan, my angels Md. Nameer Shaikh and Md. Shadaan Shaikh. 
ISSN: 2574-1241

DOI: 10.26717/BJSTR.2018.12.002236

Tarique Shaikh. Biomed J Sci \& Tech Res

(c) (P) This work is licensed under Creative

Submission Link: https://biomedres.us/submit-manuscript.php

$\begin{array}{ll}\text { BIOMEDICAL } & \text { Assets of Publishing with us } \\ \text { RESEARCHES } & \text { - Global archiving of articles } \\ & \text { - Immediate, unrestricted online access } \\ & \text { - Rigorous Peer Review Process } \\ & \text { - Authors Retain Copyrights }\end{array}$

